\title{
A note on Liouville theorem for steady Q-tensor system of liquid crystal
}

\author{
Lai Ning-An ${ }^{1}$ and Wu Jiayan ${ }^{2}$ \\ ${ }^{1}$ Lishui University \\ ${ }^{2}$ Zhejiang University
}

May 5, 2020

\begin{abstract}
We study the Liouville theorem for steady Q-tensor system of liquid crystal in $\$ \backslash \mathrm{R}^{\wedge} 3 \$$. Assuming that $\$ \mathrm{u} \backslash$ in $\mathrm{L}^{\wedge}\{\backslash$ frac 92 , $\backslash \operatorname{infty}\}\left(\backslash \mathrm{R}^{\wedge} 3\right) \backslash$ cap $\backslash \operatorname{dot}\{\mathrm{H}\}\left(\backslash \mathrm{R}^{\wedge} 3\right) \$$ and $\$ \mathrm{Q} \backslash$ in $\mathrm{H}^{\wedge} 2\left(\backslash \mathrm{R}^{\wedge} 3\right) \$$, we show that the steady system admits only trivial solution $\$ \mathrm{u}=0$, $\mathrm{Q}=0 \$$.
\end{abstract}

\section{Hosted file}

200210Liouville-covering-letter.pdf available at https://authorea.com/users/299666/articles/ 429152-a-note-on-liouville-theorem-for-steady-q-tensor-system-of-liquid-crystal 